\title{
A Multifunctional Public Lighting Infrastructure, Design and Experimental Test
}

\author{
Marco Beccali* $^{* 1}$, Valerio Lo Brano ${ }^{2}$, Marina Bonomolo ${ }^{3}$, Paolo Cicero $^{4}$, \\ Giacomo Corvisieri $^{5}$, Marco Caruso ${ }^{6}$, Francesco Gamberale ${ }^{7}$ \\ ${ }^{1}$ Dipartimento dell'Energia dell'Ingegneria dell'informazione e dei Modelli Matematici, Viale Delle \\ Scienze, Edificio 9, Palermo, Italy \\ e-mail: marco.beccali@ dream.unipa.it \\ ${ }^{2}$ Dipartimento dell'Energia dell'Ingegneria dell'informazione e dei Modelli Matematici, Viale Delle \\ Scienze, Edificio 9, Palermo, Italy \\ e-mail: lobrano@dream.unipa.it \\ ${ }^{3}$ Dipartimento dell'Energia dell'Ingegneria dell'informazione e dei Modelli Matematici, Viale Delle \\ Scienze, Edificio 9, Palermo, Italy \\ e-mail: marina.bonomolo@ deim.unipa.it \\ ${ }^{4}$ Italtel spa, Innovation Lab, SS 113 Bivio Foresta, Carini (PA), Italy \\ e-mail: paolo.cicero@italtel.com \\ ${ }^{5}$ Italtel spa, Innovation Lab, SS 113 Bivio Foresta, Carini (PA), Italy \\ e-mail: giacomo.corvisieri@italtel.com \\ ${ }^{6}$ Exalto Energy and Innovation srl, Via Giuseppe Giusti 2, Palermo, Italy \\ e-mail:m.caruso@exaltonergia.it \\ ${ }^{7}$ Exalto Energy and Innovation srl, Via Giuseppe Giusti 2, Palermo, Italy \\ e-mail: f.gamberale@exaltoenergia.it
}

Cite as: Beccali, M., Lo Brano, V., Bonomolo, M., Cicero, P., Corvisieri, G., Caruso, M., Gamberale, F., A Multifunctional Public Lighting Infrastructure, Design and Experimental Test, J. sustain. dev. energy water environ. syst., 5(4), pp 608-625, 2017, DOI: http://dx.doi.org/10.13044/j.sdewes.d5.0164

\begin{abstract}
Nowadays, the installation of efficient lighting sources and Information and Communications Technologies can provide economic benefits, energy efficiency, and visual comfort requirements. More advantages can be derived if the public lighting infrastructure integrates a smart grid. This study presents an experimental multifunctional infrastructure for public lighting, installed in Palermo. The system is able to provide smart lighting functions (hotspot $\mathrm{Wi}-\mathrm{Fi}$, video-surveillances, car and pedestrian access control, car parking monitoring and support for environmental monitoring). A remote control and monitoring platform called "Centro Servizi" processes the information coming from different installations as well as their status in real time, and sends commands to the devices (e.g. to control the luminous flux), each one provided with a machine to machine interface. Data can be reported either on the web or on a customised app. The study has shown the efficient operation of such new infrastructure and its capability to provide new functions and benefits to citizens, tourists, and public administration. Thus, this system represents a starting point for the implementation of many other lighting infrastructure features typical of a "smart city."
\end{abstract}

\section{KEYWORDS}

Multifunctional street lighting, Information and communications technology integration, Energy efficiency, Machine to machine, Lighting design, Smart lighting.

\footnotetext{
* Corresponding author
} 


\section{INTRODUCTION}

Costs of energy for public lighting often represent the main element of the expenditures for local Public Administrations (PA). Moreover, public lighting accounts for $2.3 \%$ in global electricity consumption at the national level [1]. The maintenance cost can also be relevant, while implementation of new technologies for lighting is surely a key action to achieve high-energy savings (about 30\%) [2] and contribute to reaching the 20-20-20 targets [3]. A new (and smart) public lighting infrastructure can provide a variety of benefits for citizens and the PA. First, new Light Emitting Diode (LED) lamps can significantly improve visual comfort and energy savings, while also guaranteeing safety for urban zones. A selection of appropriate luminaires, characterized by good optics, can fulfill the target of good uniformity on road plan, avoid glare, and reduce light flux dissipation toward the sky. Achieving the luminance and illuminance values suggested by technical standards, public lighting improves the safety of the city, both for traffic and for pedestrians [4]. Furthermore, good lighting improves the social aspect of the city and modifies the perception of the urban spaces, subsequently encouraging nighttime activities.

Peña-García et al. [5] conducted a survey of 275 pedestrians in a nocturnal urban environment in the city of Granada (Spain) for evaluating user perceptions of the impact of different kinds of public lighting on perceived safety from criminal actions and on general well-being, including avoidance of stress, glare, headaches, etc. They measured the average illuminance on each street to detect potential correlations between survey data, illumination levels, and the color of light. They found that well-illuminated streets where lighting is uniform, with higher illuminance levels, tend to make people feel safer and better, despite the fact that white light could lead to higher levels of light pollution. For this reason, it is worthy of interest to note the selection of luminaires, equipped with an optic that avoids the dissipation of the luminous flux above the horizontal [6]. Green et al. [7] affirmed that it was necessary to achieve sustainability gains without compromising other wellbeing outcomes for affected residents and workers. They suggested that attention should also be paid to the more symbolic effects of street light reductions as well as the direct health impacts.

Mueller et al. [8] concentrated their attention on pedestrian zones. They presented a dynamic switching of street lamps based on pedestrians' locations and desired safety (or fear) zones.

Furthermore, through the application of Information and Communications Technology (ICT) in the field of lighting, it is possible to design different scenarios for different conditions, e.g. decreasing the luminous flux when it is not necessary to have the maximum, e.g. during the night or during some day of the week. A diffuse sensors network easily placed on poles can allow the control of environmental parameters [Carbon dioxide $\left(\mathrm{CO}_{2}\right)$ emissions, noise, etc.]. This kind of data can be very useful for PA or other authorities, also, helping in increasing the awareness of the citizens about the quality of the city they live in. Traffic fluxes monitoring can help to control them better [9].

In addition, sensors can become part of a wider system of infrastructure, including an electric grid, from a perspective of supervision of local systems (nodes) by a centralized location. Cho et al. [10] proposed a street lighting control system based on LonWorks power line communication to monitor streetlight market.

A multifunctional and smart public lighting infrastructure has many features that make urban life and resource management easier. For these reasons, a smart lighting infrastructure is an essential tool for a smart city. 
Lau et al. [11] presented a model to simulate and evaluate the energy efficiency and usefulness of a real-time adaptive lighting scheme.

Jin et al. [12] studied the benefits of a pilot system of two smart city applications for public safety enhancement of a wireless networked LED street lighting system with centralized and remote control technology in a campus microgrid. Indra et al. [13] performed a similar task for a pilot project in Jakarta. Kathiresan [14] demonstrated the potential energy savings by implementing, in a real-world indoor laboratory environment, an interactive LED lighting interface using a Zig-bee based Wireless Sensor Network (WSN) for both monitoring and control of the lighting system.

Bellido-Outeiriño et al. [15] presented a smart system for managing public lighting networks based on wireless communication and the DALI protocol with wireless communication in a pilot installation. Simhas [16] presented a street lighting management system based on the use of electricity meters with extended functionality for control and monitoring of street lighting.

Jagadeesha [17] developed, implemented, and simulated low-cost sensor-based street lights that reduced energy consumption and $\mathrm{CO}_{2}$ emissions. Popa et al. [18] affirmed that the aim of a smart urban environment was to increase citizens' comfort and quality of life with minimum resources and power consumption and without affecting the natural environment. Street lighting is one of the main interests in such a smart environment. For this purpose, they implemented a lighting control system that made street lighting to an autonomous and efficient part of the smart urban environment, analyzing the performance of the proposed system using an OMNET++ network simulation. Costa et al. [19] presented an autonomous street lighting system based on solar energy as its primary source, with batteries as a secondary source, and LED as the lighting source. They underlined the advantages of using LED sources and focused on the photopic and scotopic human sensitivity in the design of the lighting system.

Many studies have been conducted on this topic. Some of these are based on simulations, while others are based on empirical data measured in laboratory applications or pilot projects in different cities. It is interesting to analyze and compare the performance and results. This paper presents a smart lighting system composed of multifunctional poles with a remote control. The system was installed in two different locations and its performance was tested and monitored over last year. The two systems, one in Palermo and one in Carini (Italy), are functionally connected to a management node called the Centro Servizi [20]. The project and its correlated test has been conducted within the research project "Innovation for greeN Energy and eXchange in Transportation" (iNext) which was funded by the Italian Ministry of University and Research in the framework of the Smart Cities and Communities and Social Innovation program.

The Centro Servizi realizes the first concrete change of approach from the "pipe oriented" (an appliance for each vertical use case) to the "layer oriented" (an applicative framework for any vertical use case) in an Internet Of Things (IOT) system for a Smart City. It has enabled the management of any IOT context (energy, lighting, mobility) through the same IOT applicative framework based on an inexpensive, non-redundant, cooperative, scalable, and real-time IOT platform (endorsed to Machine to Machine -European Telecommunications Standard Institute standard), with an easy evolution foreseen to one Machine to Machine (M2M). Use cases for smart lighting, mobility, parking, and energy management have been implemented and more use cases can be quickly and easily added. Furthermore, a low-cost, Arduino-based smart adapter has been developed to link any peripheral device or sensor to the Centro Servizi, due to its protocol-adapting, M2M management, and device-specific command execution features. 


\section{SMART PUBLIC LIGHTING SYSTEM}

Several studies and installations of smart lighting infrastructures have been implemented and studied in the last few years. In general, it is interesting to note the definition of "Smart Street" given by Annunziato et al. [21], a street characterized by a smart lighting infrastructure composed of multifunctional smart lighting poles; they are propelled by several devices that can give different functions and services $\left(\mathrm{CO}_{2}\right.$ sensors, traffic sensors, etc.) [22] and can communicate through an advanced communication system (e.g. powerline networking and web interaction). Moreover, they share data with a central system that tracks the tasks and activities of the city (i.e. people, vehicles, emissions, etc.) and regulate the luminous flux point by point. The purpose of a smart street is to improve urban environment, achieve relevant energy savings, and decrease lighting pollution. Technologies available today can operate on switch on-off actions, voltage stabilization, remote monitoring, and control (dimming) of luminous flux.

It must be noted that, in general, the lighting systems are often selected to provide long periods of high luminous flux instead of the required minimum values. Lamps generally wear out over time and their luminous flux decreases during that time. To better fulfill their purpose, lamps are used from the beginning of their operation until a certain standard of luminance values. For this reason, lamps begin life with luminous flux $30-35 \%$ higher than the target luminance. The lighting control system regulates the power and applies $100 \%$ power only during the last part of the lamp life. The installation of a control system contributes strongly to achieving energy savings. Nevertheless, it is generally not easy to integrate most of these technologies with pre-existing systems, with the exception of their installation in point-to-point schemes. Moreover, many modern control cycles have an "open architecture". The control systems are not linked to sensors that measure environmental parameters and traffic conditions. In fact, the lighting strategies are defined a priori and do not depend on the environmental conditions or to the presence of vehicles or pedestrians.

\section{THE GENERAL FRAMEWORK OF THE INFRASTRUCTURE}

A multifunctional infrastructure composed of 16 lighting poles with a remote control system was designed and installed in the iNext (PON04a2_H) project, funded by the Italian Ministry of University and Research in the framework of the PON Smart Cities and Communities and Social Innovation. It was designed to provide many additional services such as motion detection, parking control, Wi-Fi hot spots, and video-surveillance.

The infrastructure is equipped with many ICT devices as well as advanced lighting equipment. The design goals were:

- Installation of efficient lamps;

- Adoption of optics to avoid the dispersion of the luminous flux above the horizontal;

- Installation of lamps characterized by high Colour Rendering Index (CRI);

- Installation of advanced light control systems;

- Installation of sensor systems able to monitor many environmental parameters;

- Installation of other services and tools like apps and a Wi-Fi connection;

- Voltage stabilization.

The "mission" of the infrastructures was based on:

- The achievement of energy savings for urban lighting, regulating the luminous flux with remote or local control, through motion detection by Closed Circuit Television (CCTV), and measuring electrical consumption of the system or of a single fixture;

- Real scale test of a multifunctional infrastructure solution for the PA, including environmental parameter monitoring, traffic light controls, multifunctional lighting poles, video-surveillance system, and variable messages panels; 
- Real scale test of a multifunctional infrastructure solution for citizens that included Wi-Fi, smart communities, tele-assistance, and energy monitoring;

- Real scale test of a multifunctional infrastructure solutions for the utilities that included electricity and system monitoring of renewable sources.

The tests areas included the campus of the University of Palermo and the Italtel company headquarters in Carini (Pa). Both locations are part of a test network, including additional facilities in the same areas and in Capo d'Orlando (Messina). In other words, these systems are integrated in a wide platform where several infrastructure elements and nodes can interact: electric car charging stations, proactive users, energy producers (photovoltaic, micro wind) and storages. The main node of the ICT network is called the Centro Servizi and this is connected to the remote physical infrastructure through local Internet gateways. These devices provide local aggregation of physical infrastructure and devices; adaptation of communication protocols and data exchange; and local delivery of other ICT services.

Figure 1a shows the network link to the Centro Servizi with the local infrastructure and how the communication works between the devices. As highlighted in the figure, the current solution was developed with the multi-functional features and Ethernet/PLC link of the i-Next project. This layout has effective results but some applications that require more bandwidth can be disadvantaged. A pending upgrade will use an optical router with new network links and interfaces (Figure 1b). In this way, a number of applications can be integrated due to the availability of larger bandwidth.

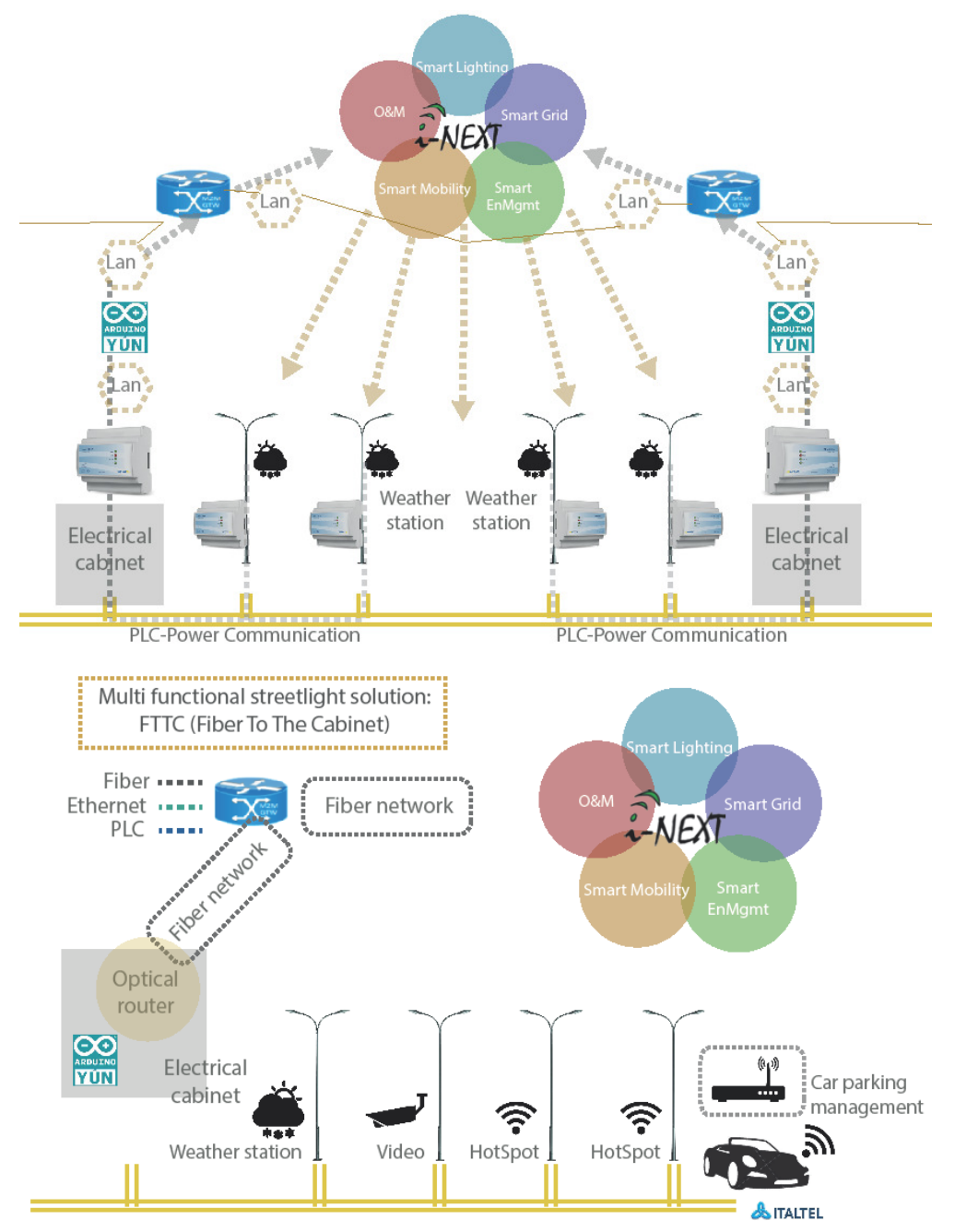

Figure 1. Architecture scheme of the network domain (with detail of NACsPaloApp): existing (a) and further expected upgrade (b) 
The ICT platform communicates with external devices and apps through the gateways. Devices are connected and controlled through an Arduino board, which is basically a low-cost microcontroller with complementary components that facilitate programming hardware control with very low energy requirements. On the other side, the gateway is linked to users using Web applications or specific Graphic Users Interfaces (GUI).

The software architecture is shown in Figure 2. In the network domain of the ICT platform, the multipurpose poles module is dedicated to the management of the lighting infrastructure. One of its dynamic components, the AppBusinessManager, handles data coming from the field and from the database. This app associates specific actions to inputs according to embedded algorithms developed for the set of "operation cases." External web applications can also include Android apps for smart phones and tablets. An application server acts as app gateway handling the data exchange between apps and ICT platform and apps and local devices.

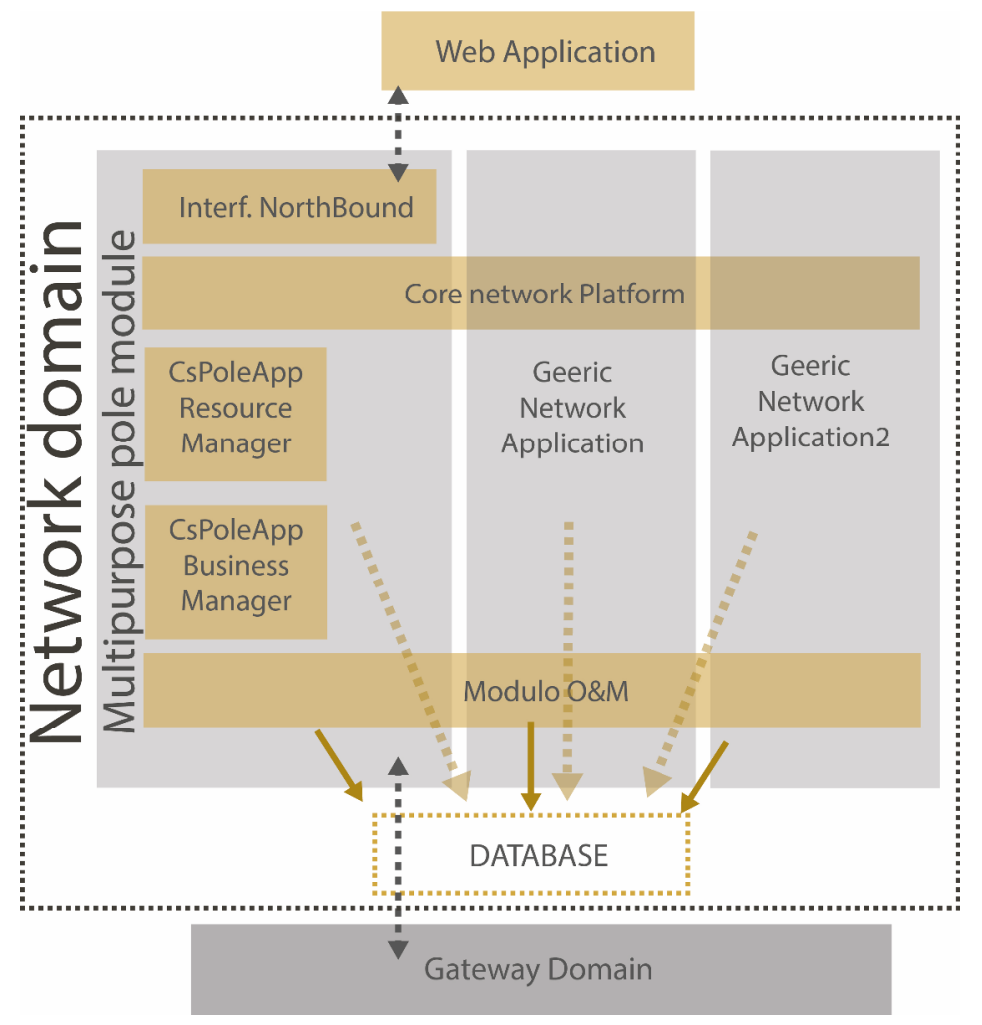

Figure 2. Software network domain

\section{MULTIFUNCTIONAL PUBLIC LIGHTING SYSTEM AT UNIPA AND ITALTEL BASE}

One of the main functions for users of the tested infrastructures was to provide public lighting. In an area of the University of Palermo campus, eight fixtures equipped with high-pressure, $400 \mathrm{~W}$ sodium lamps were replaced with new LED lamps (Figure 3). Moreover, other devices (CCTV, sensors, etc.) were installed on two of the poles (Figure 4). The fixtures were installed on the existing whip-type tapered, $10 \mathrm{~m}$ poles.

Power Line Networking (PLN) is used for local data transmission [23]. The luminaires are connected to a switchboard that also hosts the communication module based on the Arduino board. A CCTV system was installed on another pole in addition to the eight poles previously described. The motion detection camera installed on one of the original eight poles was a "bullet water-proof outdoor" camera with 2 MP resolution and an integrated Information Retrieval (IR) system. 


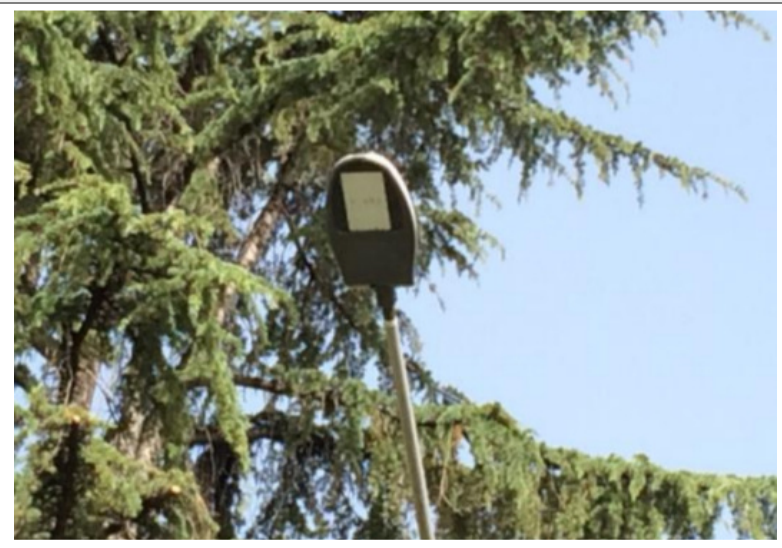

Figure 3. New LED luminaire

The selected luminaires were 48 LED elements supplied by an electric current of $700 \mathrm{~mA}$. Their nominal luminous flux was $11,900 \mathrm{~lm}$ with a rated power of $118 \mathrm{~W}$. The same luminaires were installed in Carini.

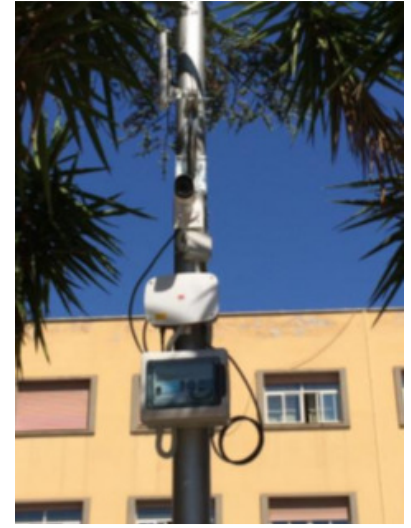

Figure 4. Pole with additional devices

The architecture, infrastructure, and software were designed to provide several functions related to different scenarios:

- Light dimming and on/off control: lamps are regulated according to time schedules and available natural lighting levels;

- Light on rain: lamps are switched on during daytime in case of storms or hard rain;

- Light on motion: the luminous flux increases if there are pedestrians or vehicles;

- Light on visibility reduction: the luminaires are switched on during daytime in case of reduction of daylight due to clouds or fog;

- Parking search: searching of free parking (only in Carini);

- Parking check: controlling reserved parking spaces for "car sharing" to identify unauthorized parking (only in Carini);

- Extension of Wi-Fi, using the infrastructure and data transport through Power Line Networking (PLN).

The "Smart Light" smartphone app (Figure 5), developed by project partner Exalto, can be used to control and monitor the lighting systems in Palermo and Carini [24]. For both locations, users can read the system status (i.e. up when all the devices are turned on, degraded if some device is failing, or down when all the devices are turned off). Using a map view, it is possible to check the status of each pole and to set its operations (on/off, dimming). Moreover, it is also possible to read data from the sensors embedded in the poles. 

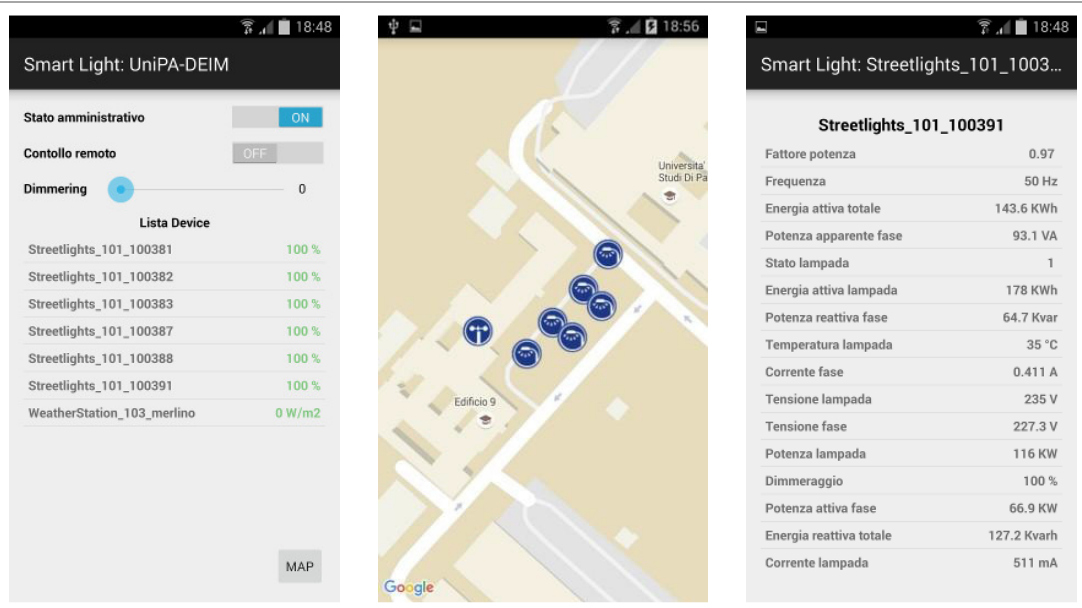

Figure 5. Screenshots of the Smart Light smartphone app

\section{LIGHTING SIMULATIONS AND DESIGN}

The general layout of the area is depicted in Figure 6.

Many lighting simulations (Figures 7 and 8) have been performed with the Dialux 4.12 [25] simulation software to select the LED luminaires and verify whether the luminance values provided by the system fulfill the standard UNI 13201 [26] requirements for the road categories indicated in UNI11248 [27]. In particular, a speed limit of $30 \mathrm{~km} / \mathrm{h}$ is indicated for the campus of Palermo. According to the standard, the road can be S3 category (Urban local roads), or, CE4 category (Urban local roads: town centre, low traffic isles, zone 30) or CE5 category (Urban local roads: other situations). As shown in Table 1, a minimum value of horizontal illuminance of 7.5 lux is necessary for $\mathrm{S} 3$ roads, 10 lux for CE4 roads and 7.5 lux for CE5 roads. One of the main functions for end users of the tested infrastructure was to provide public lighting. In an area of the University of Palermo campus, eight fixtures equipped with high-pressure, $400 \mathrm{~W}$ sodium lamps were replaced with new LED lamps. Moreover, CCTV and sensors were installed on two of whip-type, $10 \mathrm{~m}$ tapered poles.

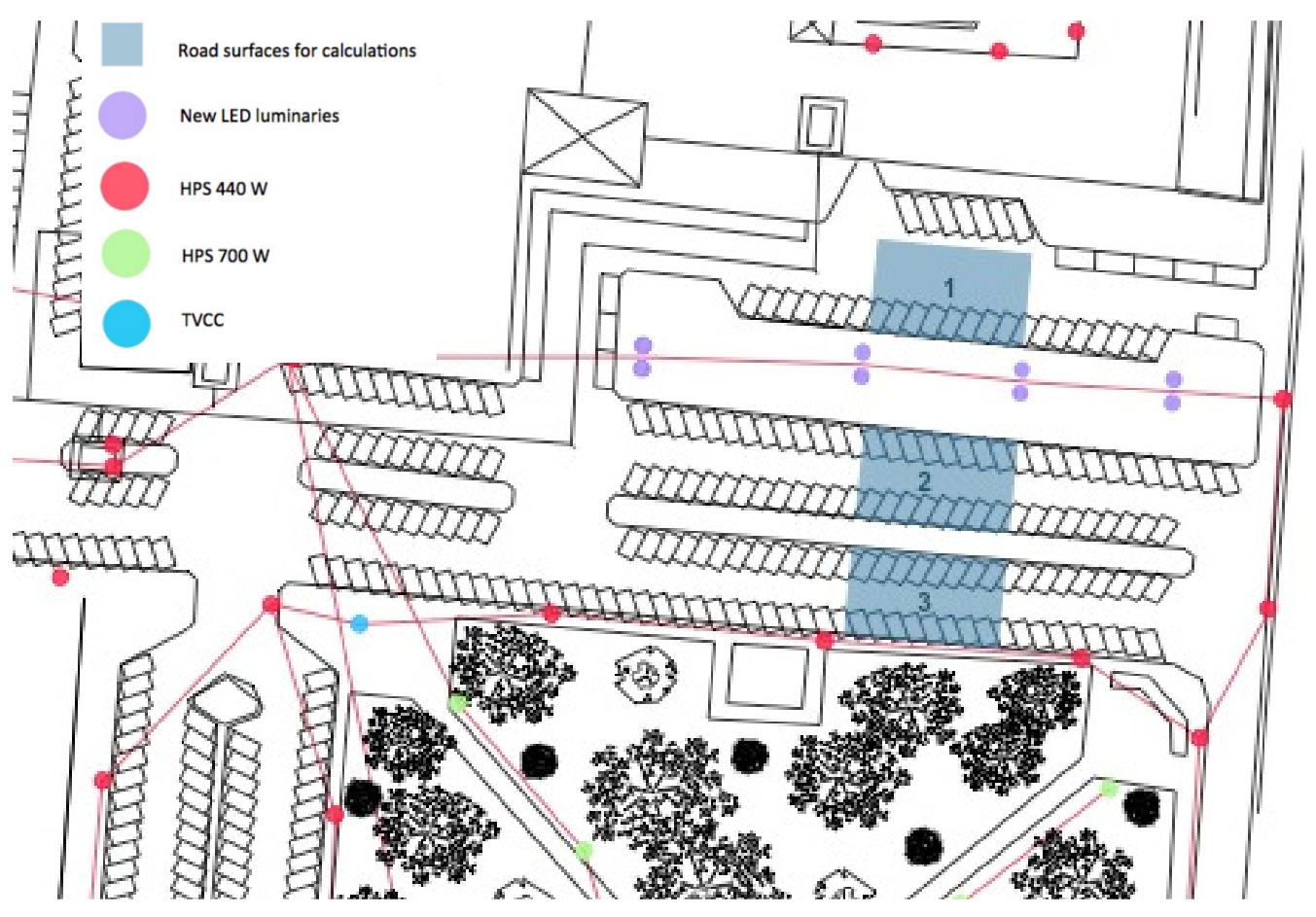

Figure 6. Plan of the area 


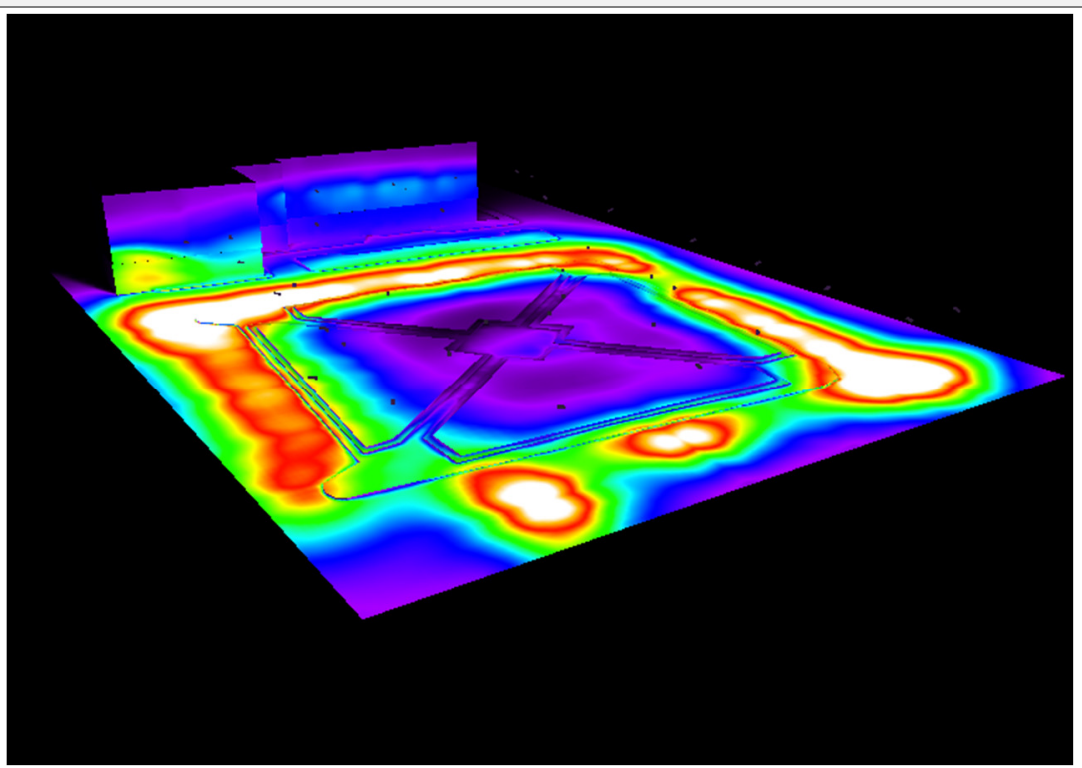

Figure 7. False color rendering of the installation of University of Palermo

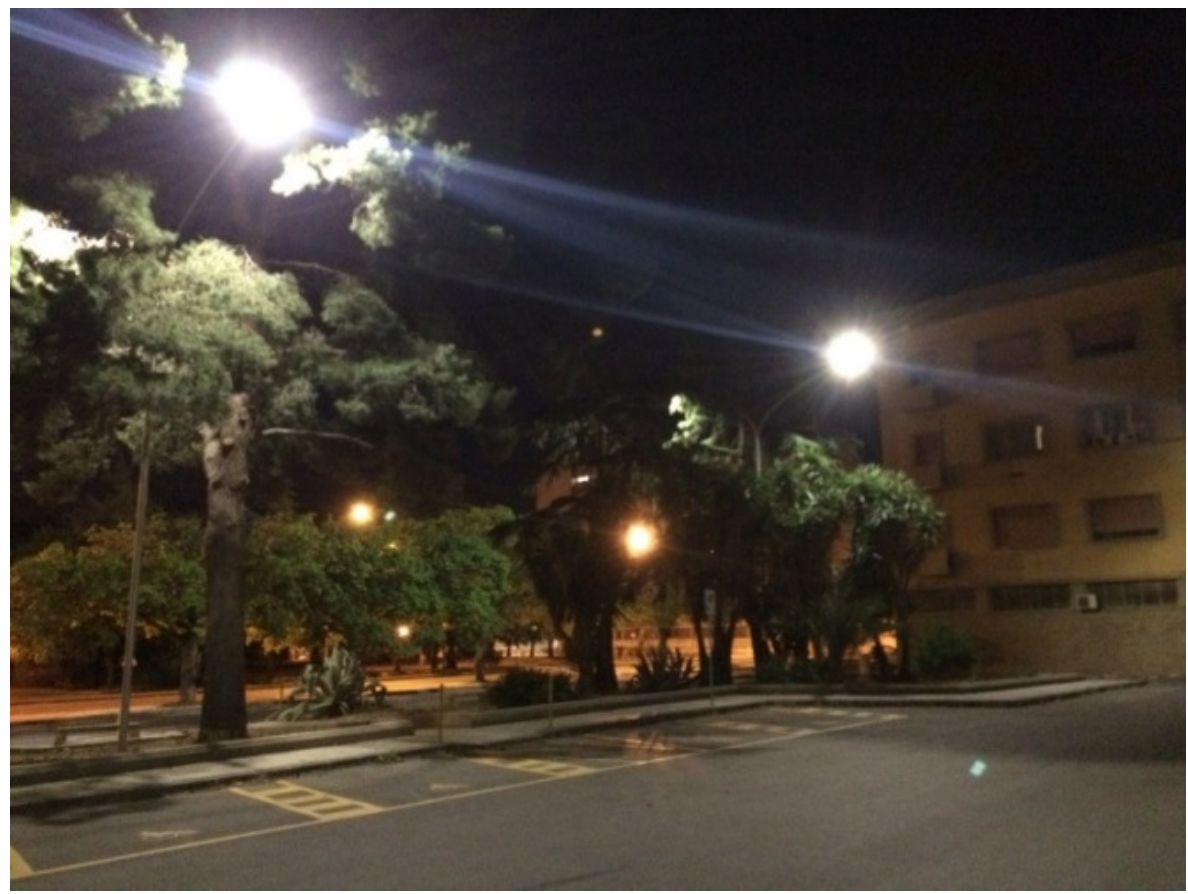

Figure 8. The luminaires installed at University of Palermo

Table 1. Lighting classification (UNI 11248) with the horizontal illuminance values, and the General Uniformity

\begin{tabular}{ccc}
\hline Roads categories & Minimum horizontal illuminance [lux] & General Uniformity \\
\hline S3 & 7.5 & 1.5 \\
CE4 & 10 & 0.4 \\
CE5 & 7.5 & 0.4 \\
\hline
\end{tabular}

The illuminance values of HPS lamps were higher than the values reported in Table 2, with values between 50 and $100 \mathrm{~lx}$ measured on the road surface. Simulations were conducted between two lights on a road. It must also be noted that the new lamps have a greater CRI, ensuring better conditions of visual comfort. 
Table 2. Calculation of illuminance values for three road surfaces (see Figure 6)

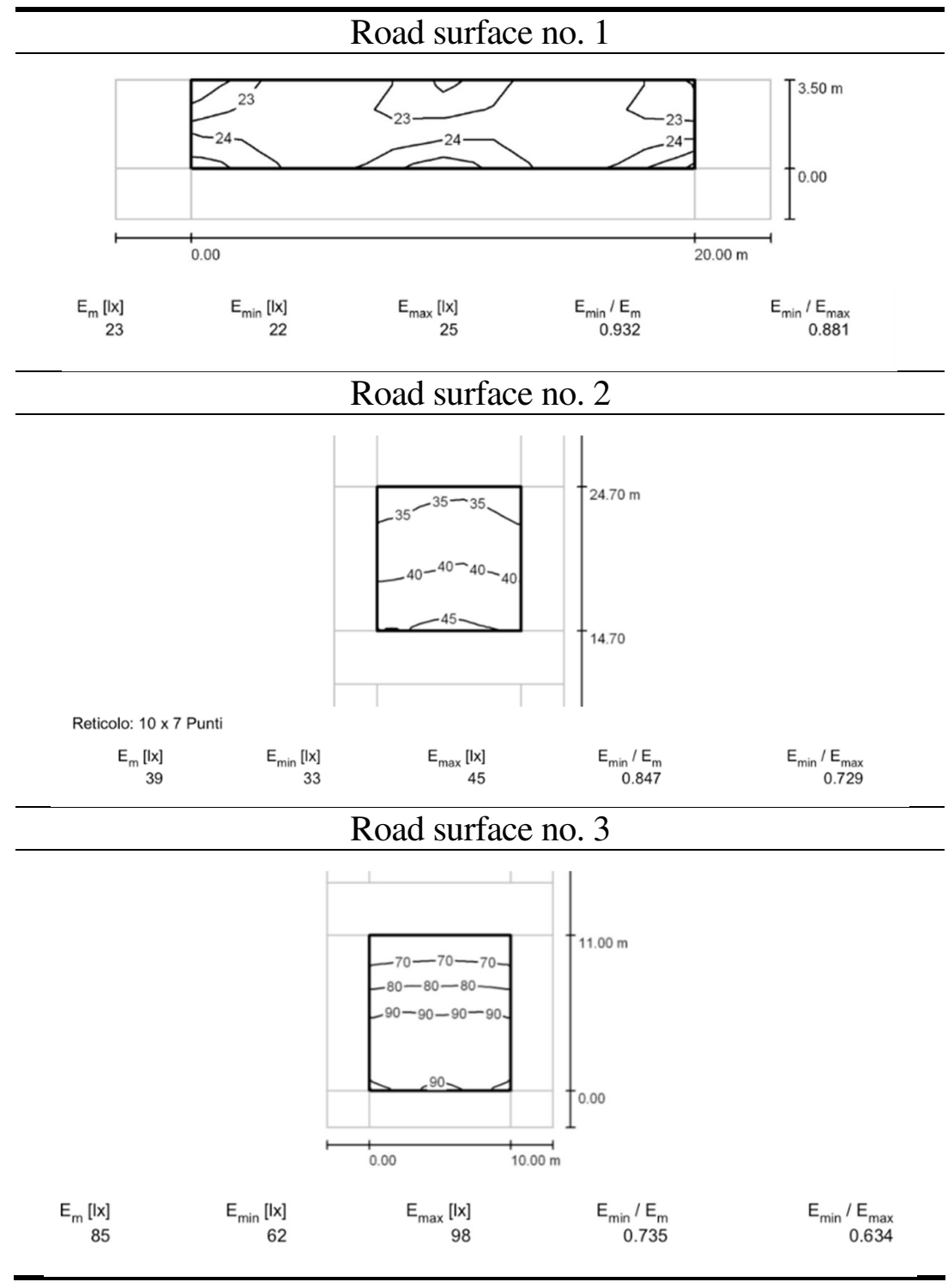

Electricity consumption has been measured and monitored during three periods. During the first period, the HPS lamps were locally driven by a twilight switch. It was regulated with a luminance threshold of $200 \mathrm{~lx}$, as measured by the sensor, while the measured illuminance on the road surface level was 600 lx. During the second test period, the LED lamps were regulated by an analog timer, while more complex logic was implemented for the third test period.

An algorithm was developed to switch the lamps on and off and to dim them during the tests, such that the luminous flux of the lamps was $100 \%$ for the first ten minutes, after which they were dimmed to a value somewhere above $20 \%$. The logic control was based on the measurements of global solar radiation taken by the weather station placed in the front building. To correlate these measurements to reliable values of illuminance on the road plan, an empirical rule was set on the basis of several measurements [28].

The following rules and threshold were calibrated through a detailed hourly simulation of the illuminance field during the year. RAD is the global horizontal solar radiation in $\mathrm{W} / \mathrm{m}^{2}$. During sunrise, sunset:

- Luminous flux at 50\%;

- If RAD > 15;

○ Luminous flux at $0 \%$. 
During sunrise the luminous flux is set to $50 \%$ as well as the case of low illuminance during the day, the luminous flux was set to $50 \%$.

\section{CONSUMPTION BASELINE AND EXPECTED SAVINGS}

To create a baseline for the calculation of energy savings, ex ante consumption (unfortunately not previously measured for a long period) was estimated. As previously stated, the HPS lamps were connected to a switchboard equipped with a light sensor. Lamps were switched on when road illuminance fell below 600 lux and switched off when daylight levels overcame the threshold. To have a reasonable hourly time series of horizontal luminance during every day of the year, the Meteonorm database [29] was used.

For every $15^{\text {th }}$ day of the month, an hourly profile of on/off switching of the lamps was simulated on the basis of such values. Table 3 shows the on and off times for each month and the correspondent estimated electric consumption.

Table 3. Assessment of operation time and electricity consumption of HPS lamps

\begin{tabular}{ccccccc}
\hline Month & Time ON & Time OFF & $\begin{array}{c}\text { Daily } \\
{[\text { hours }]}\end{array}$ & $\begin{array}{c}\text { Monthly } \\
{[\text { hours }]}\end{array}$ & $\begin{array}{c}\text { Power } \\
{[\mathrm{W}]}\end{array}$ & $\begin{array}{c}\text { Consumption } \\
{[\mathrm{kWh}]}\end{array}$ \\
\hline January & 17.30 & 8.30 & 15.0 & 465.0 & 3,200 & $1,488.0$ \\
February & 17.30 & 7.30 & 14.0 & 392.0 & 3,200 & $1,254.4$ \\
March & 18.30 & 7.00 & 12.5 & 387.5 & 3,200 & $1,240.0$ \\
April & 19.30 & 6.30 & 11.0 & 330.0 & 3,200 & $1,056.0$ \\
May & 19.30 & 5.30 & 10.0 & 310.0 & 3,200 & 992.0 \\
June & 19.30 & 5.30 & 10.0 & 300.0 & 3,200 & $1,041.6$ \\
July & 19.30 & 5.30 & 10.0 & 310.0 & 3,200 & 992.0 \\
August & 19.30 & 6.00 & 10.5 & 325.5 & 3,200 & $1,041.6$ \\
September & 18.30 & 6.30 & 12.0 & 360.0 & 3,200 & $1,152.0$ \\
October & 18.00 & 7.30 & 13.5 & 418.5 & 3,200 & $1,339.2$ \\
November & 17.30 & 8.00 & 14.5 & 435.0 & 3,200 & $1,392.0$ \\
December & 16.30 & 8.00 & 15.5 & 480.5 & 3,200 & $1,537.6$ \\
\hline Total & & & & $4,514.0$ & 38,400 & $14,526.4$ \\
\hline
\end{tabular}

In this way, the estimated yearly electricity consumption before the installation was $14,526 \mathrm{kWh}$.

During the design phase, a preview of achievable savings was also performed. Three time ranges were defined for each month, according to the hourly daylight availability and the expected presence of users in the area. A dimming factor was associated with each of them (Table 4). The first one requires $100 \%$ lighting and corresponds to hours when daylight is not available, but the area is normally used. The second time range deals with nighttime hours when dimming can be set to $50 \%$ because of the scarcity or lack of people. The third range corresponds to sunrise, with a dimming factor equal to $75 \%$.

The assessed yearly consumption was approximately equal to $2,900 \mathrm{kWh}$, with a savings of about $11,650 \mathrm{kWh}$ per year. Some spot measurements of daily consumption of the previous system made in December 2014 and January 2015 confirmed such figures, with daily consumption around $50 \mathrm{kWh}$.

Further measurements were performed with the new system. Three different operations have been monitored, including local operation with on/off control based on a pre-set time schedule and no dimming (summer 2015), local operation with continuous 
dimming based on global radiation (summer 2015) and remote operation from Centro Servizi with continuous dimming based on global radiation and additional controls for other events (heavy rain, light on motion, etc.) (December 2015-January 2016).

Table 4. Assessment of operation time and electricity consumption of LED lamps with dimming

\begin{tabular}{|c|c|c|c|c|c|}
\hline Month & Time & $\begin{array}{l}\text { Dimming } \\
\text { factor }\end{array}$ & $\begin{array}{l}\text { Dimmed } \\
\text { power [W] }\end{array}$ & $\begin{array}{c}\text { Total daily } \\
\text { operation hours }\end{array}$ & $\begin{array}{c}\text { Monthly energy } \\
\text { consumption } \\
{[\mathrm{kWh}]}\end{array}$ \\
\hline \multirow[t]{3}{*}{ January } & $17: 00-22: 00$ & $100 \%$ & 944 & 5.0 & 14.3 \\
\hline & $22: 00-7: 00$ & $50 \%$ & 472 & 9.0 & 131.7 \\
\hline & 7:00 - 8:00 & $75 \%$ & 708 & 1.0 & 21.9 \\
\hline \multirow[t]{3}{*}{ February } & $17: 00-22: 00$ & $100 \%$ & 944 & 5.0 & 132.2 \\
\hline & $22: 00-6: 30$ & $50 \%$ & 472 & 8.5 & 112.3 \\
\hline & $6: 30-7: 30$ & $75 \%$ & 708 & 1.0 & 19.8 \\
\hline \multirow[t]{3}{*}{ March } & $18.00-22: 00$ & $100 \%$ & 944 & 4.0 & 117.1 \\
\hline & $22: 00-6: 00$ & $50 \%$ & 472 & 8.0 & 117.1 \\
\hline & $6: 00-7: 00$ & $75 \%$ & 708 & 1.0 & 21.9 \\
\hline \multirow[t]{3}{*}{ April } & $18: 30-22: 00$ & $100 \%$ & 944 & 3.5 & 102.4 \\
\hline & $22: 00-5: 00$ & $50 \%$ & 472 & 7.0 & 99.1 \\
\hline & $5: 00-6: 00$ & $75 \%$ & 708 & 1.0 & 21.2 \\
\hline \multirow[t]{3}{*}{ May } & $20: 00-22: 00$ & $100 \%$ & 944 & 2.0 & 56.6 \\
\hline & $22: 00-5: 30$ & $50 \%$ & 472 & 7.5 & 109.7 \\
\hline & $5: 30-6: 30$ & $75 \%$ & 708 & 1.0 & 21.9 \\
\hline \multirow[t]{3}{*}{ June } & $20: 30-22: 00$ & $100 \%$ & 944 & 1.5 & 43.9 \\
\hline & $22: 00-5: 30$ & $50 \%$ & 472 & 7.5 & 106.2 \\
\hline & $5: 30-6: 30$ & $75 \%$ & 708 & 1.0 & 21.2 \\
\hline \multirow[t]{3}{*}{ July } & $20: 30-22: 00$ & $100 \%$ & 944 & 1.5 & 42.5 \\
\hline & $22: 00-5: 30$ & $50 \%$ & 472 & 7.5 & 109.7 \\
\hline & $5: 30-6: 30$ & $75 \%$ & 708 & 1.0 & 21.9 \\
\hline \multirow[t]{3}{*}{ August } & $20: 00-22: 00$ & $100 \%$ & 944 & 2.0 & 58.5 \\
\hline & $22: 00-6: 00$ & $50 \%$ & 472 & 8.0 & 117.1 \\
\hline & $6: 00-7: 00$ & $75 \%$ & 708 & 1.0 & 21.9 \\
\hline \multirow[t]{3}{*}{ September } & $19: 00-22: 00$ & $100 \%$ & 944 & 3.0 & 87.8 \\
\hline & $22: 00-6: 30$ & $50 \%$ & 472 & 8.5 & 120.4 \\
\hline & $6: 30-7: 30$ & $75 \%$ & 708 & 1.0 & 21.2 \\
\hline \multirow[t]{3}{*}{ October } & $17: 30-22: 00$ & $100 \%$ & 944 & 4.5 & 127.4 \\
\hline & $22: 00-6: 00$ & $50 \%$ & 472 & 8.0 & 117.1 \\
\hline & $6: 00-7: 00$ & $75 \%$ & 708 & 1.0 & 21.9 \\
\hline \multirow[t]{3}{*}{ November } & $16: 30-22: 00$ & $100 \%$ & 944 & 5.5 & 155.8 \\
\hline & $22: 00-6: 30$ & $50 \%$ & 472 & 8.5 & 120.4 \\
\hline & $6: 30-7: 30$ & $75 \%$ & 708 & 1.0 & 21.2 \\
\hline \multirow[t]{3}{*}{ December } & $16: 30-22: 00$ & $100 \%$ & 944 & 5.5 & 161.0 \\
\hline & $22: 00-7: 00$ & $50 \%$ & 472 & 9.0 & 131.7 \\
\hline & $7: 00-8: 00$ & $75 \%$ & 708 & 1.0 & 21.9 \\
\hline Yearly total & & & 2,8 & & \\
\hline
\end{tabular}


A sample of the measurements is reported in Table 5.

Table 5. Sample of measures and calculations of average daily consumption

\begin{tabular}{|c|c|c|c|c|c|}
\hline $\begin{array}{c}\text { System's } \\
\text { configuration }\end{array}$ & Date & Hour & Days & $\begin{array}{c}\text { Consumption } \\
{[\mathrm{kWh} / \mathrm{d}]}\end{array}$ & $\begin{array}{l}\text { Energy } \\
\text { saving }\end{array}$ \\
\hline \multicolumn{6}{|c|}{$\begin{array}{l}\text { HSP poles, timer and twilight } \\
\text { switch (Dec 2014-Jan 2016) }\end{array}$} \\
\hline & $27 / 12 / 14$ & $12: 00$ & 1 & 50.9 & \\
\hline & $7 / 1 / 15$ & 11:00 & 11 & 49.3 & \\
\hline & $9 / 1 / 15$ & $10: 00$ & 2 & 48.1 & \\
\hline & & & Average & 49.2 & \\
\hline \multirow{4}{*}{$\begin{array}{l}\text { Installation of } \\
\text { the new LED } \\
\text { system } \\
\text { LED, timer } \\
\text { (summer 2015) }\end{array}$} & $13 / 5 / 15$ & & & & \\
\hline & $11 / 6 / 15$ & 09:30 & 22 & 17.6 & \\
\hline & $23 / 7 / 15$ & $10: 00$ & 64 & 22.5 & (estimated) \\
\hline & & & Average & 21.2 & $33.66 \%$ \\
\hline \multicolumn{6}{|l|}{$\begin{array}{c}\text { LED, local } \\
\text { dimming } \\
\text { (summer 2015) }\end{array}$} \\
\hline & $24 / 7 / 15$ & 09:30 & 1 & 9.7 & \\
\hline & $27 / 7 / 15$ & $11: 00$ & 3 & 6.9 & \\
\hline & $28 / 7 / 15$ & 09:30 & 1 & 6.9 & \\
\hline & $29 / 7 / 15$ & 09:30 & 1 & 8.3 & \\
\hline & $30 / 8 / 15$ & $10: 00$ & 32 & 0.2 & (estimated) \\
\hline & & & Average & 6.6 & $79.50 \%$ \\
\hline \multicolumn{6}{|c|}{$\begin{array}{c}\text { LED, dimming and control from } \\
\text { "Centro Servizi" } \\
\text { (Dec 2015-Jan 2016) }\end{array}$} \\
\hline & $23 / 12 / 15$ & $10: 11$ & 1 & 27.56 & \\
\hline & 7/1/16 & $09: 38$ & 15 & 27.40 & \\
\hline & $8 / 1 / 16$ & $09: 34$ & 1 & 25.62 & \\
\hline & $11 / 1 / 16$ & $09: 36$ & 3 & 26.92 & \\
\hline & & & Average & 27.25 & $44.61 \%$ \\
\hline
\end{tabular}

As shown in Table 5, the new LED system guaranteed very low consumption after HPS lamps (old system) were installed. Measurements highlighted the fact that the energy savings was around $44.6 \%$ during the winter. The observed periods were: Dec 2014-Jan 2015 for the old system and Dec 2015-Jan 2016 for the new system. In this period, the new system was operated by the Centro Servizi facility according to the control rules previously mentioned.

Consumption measured during summer operation was largely lower. In this case, the baseline was the estimated consumption for the period. Results have demonstrated energy savings of $33.7 \%$ when the LED on/off control was exclusively operated by a local timer and $79.5 \%$ when the LED lights were controlled by the system based on solar radiation data. 


\section{ADDITIONAL FEATURES}

The "Parking search" and "Parking check" scenarios were tested in Carini, while the "Light on heavy rain" and the "Light on motion" functions were tested in both setups.

The following scheme (Figure 9) shows how the Radio-Frequency Identification (RFID) reader detected the parked car and transmitted the information to the Centro Servizi. A picture of the installation is shown in Figure 10.

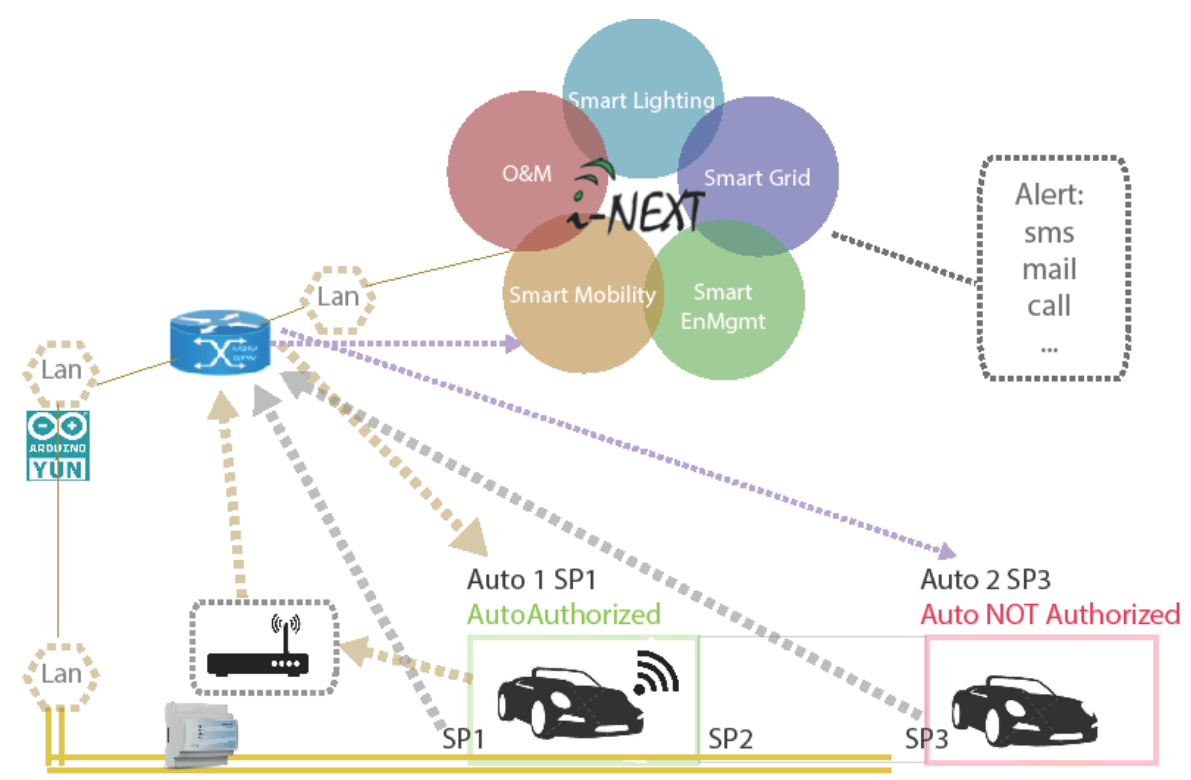

Figure 9. Parking check: detection of unauthorized (SP3) and authorized cars (SP1)

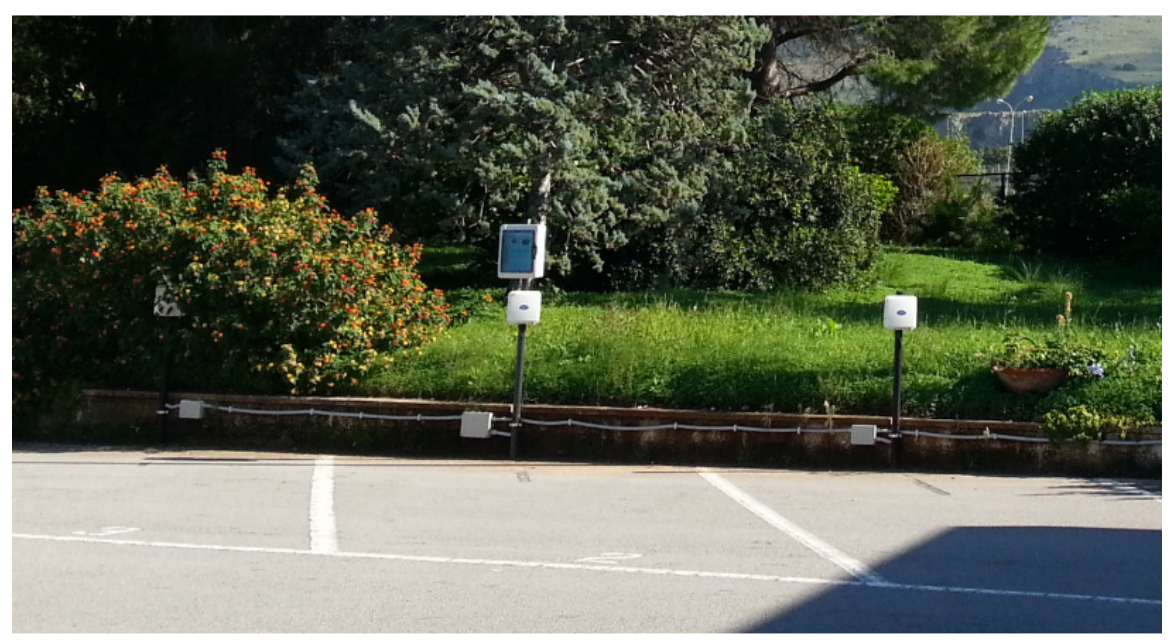

Figure 10. RFID reader

Another smartphone app was developed by Exalto to help users find parking. The app gives users a picture of the occupation status of each monitored parking lot. On the other hand, the Municipal Mobility Authority (AMAT) has started to test this function through a Web application with the aim of controlling the public car sharing areas.

Motion-activated cameras were used for two purposes. The first purpose was to gather and handle data regarding the presence of moving or still cars and pedestrians in the area (Figure 11). These data can also be used for scopes as traffic info and traffic light control. Future elaborations have been envisaged to develop forecast models of traffic and road use, which could subsequently be used to tune the availability of other infrastructure such us pubic lighting. 


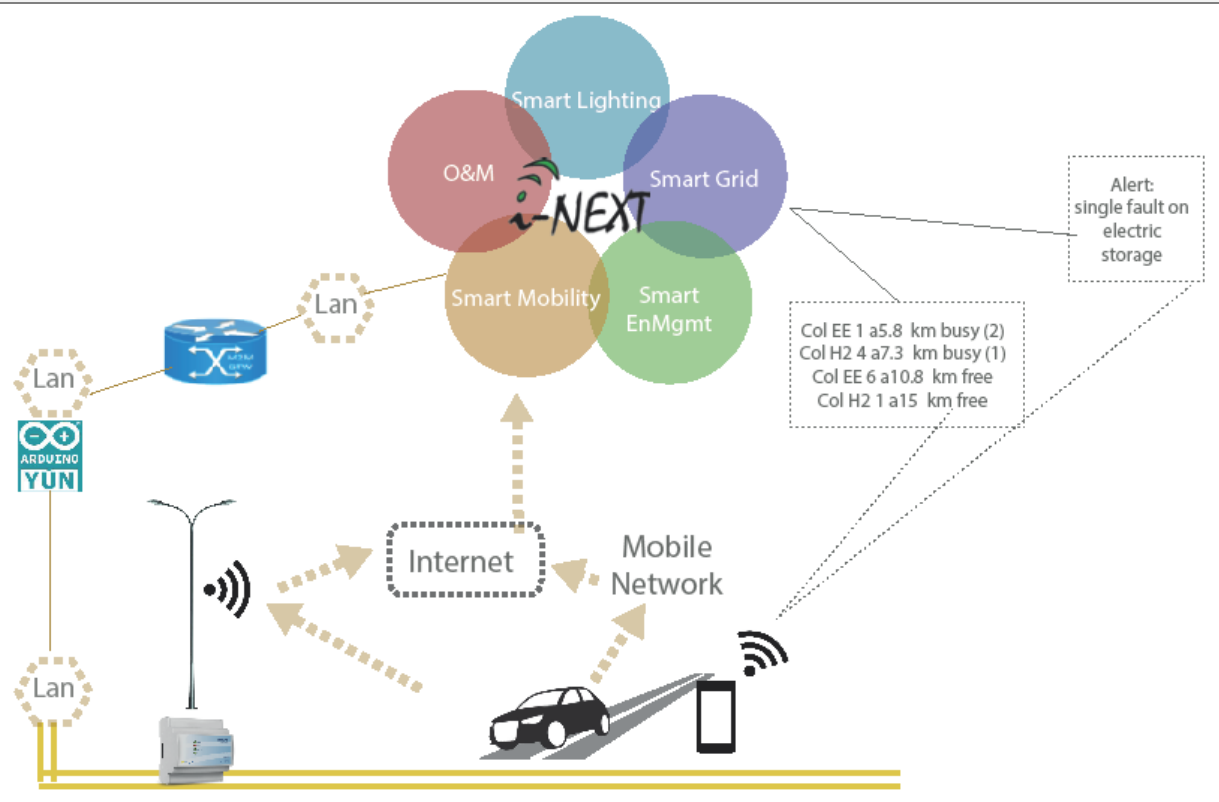

Figure 11. Scheme of the traffic monitoring/alerting scenario

The second purpose, as shown in Figure 12, of the motion-activated cameras was to turn on the lighting system at the maximum dimming for cars or pedestrians in the area. This will provide additional lighting to temporally upgrade visual comfort for drivers and pedestrians. In addition, the same function can be activated for sensible areas where a safer environment can be granted for pedestrians. Furthermore, IC power-supply pin $\left(\mathrm{V}_{\mathrm{CC}}\right)$ recording and alerting can be operated more precisely.

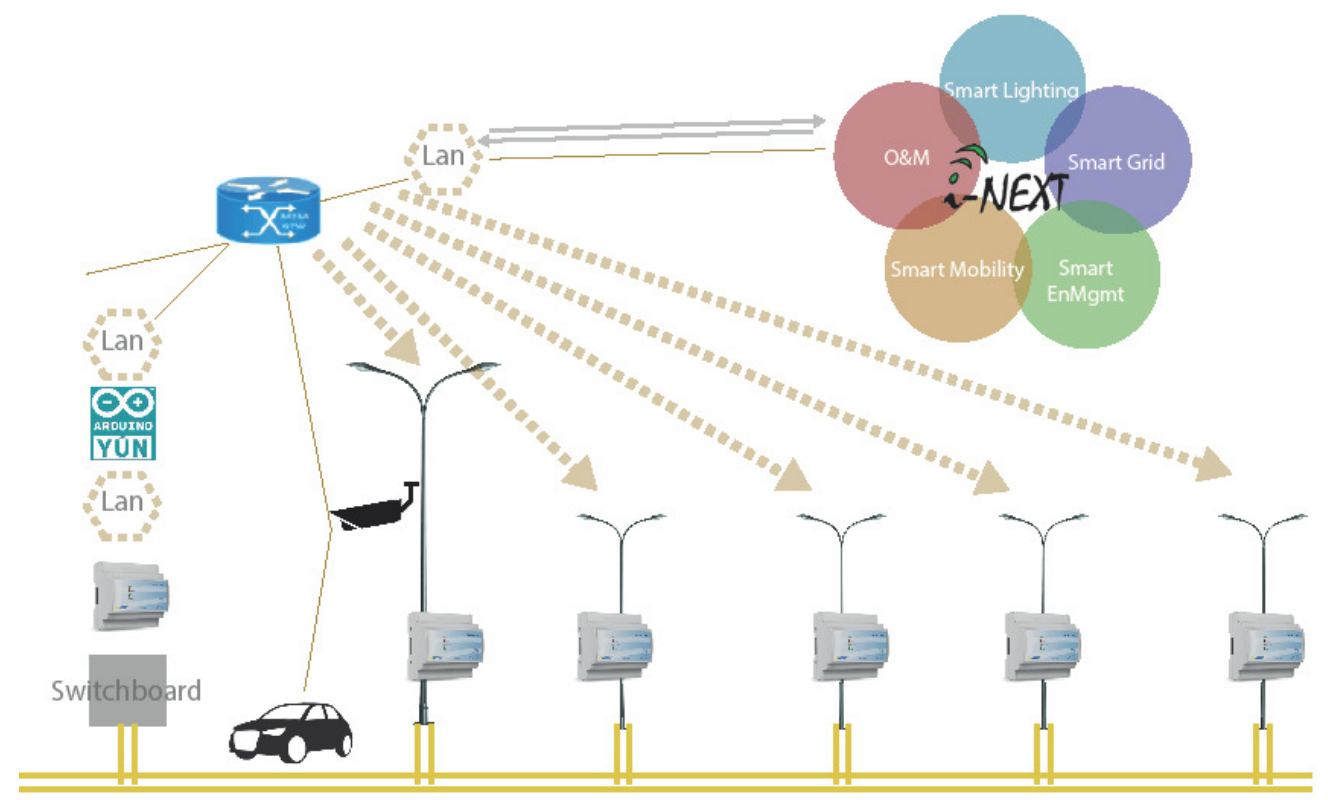

PLC-Powerline Comunication

Figure 12. Scheme of the "light on motion" scenario trough the PLC

\section{WEB APPLICATIONS}

As previously mentioned, the Centro Servizi can control and monitor several remote infrastructure elements. Two smart gateways, M2M and ETSI, were installed in Palermo and Carini. The devices communicate with the infrastructure to send and receive information. A web application displays the measured data, allows control of 
events-actions during operation, monitors the status of each device, and performs other functions. In particular, the measured data includes dimming percentage, electric current, active energy of the lamps, active energy of the system, reactive energy of the lamps, reactive energy of the system, power of the lamps, frequency, lamps status, potential difference, and temperature of the luminaire.

Figure 13 displays some screenshots of the web application.

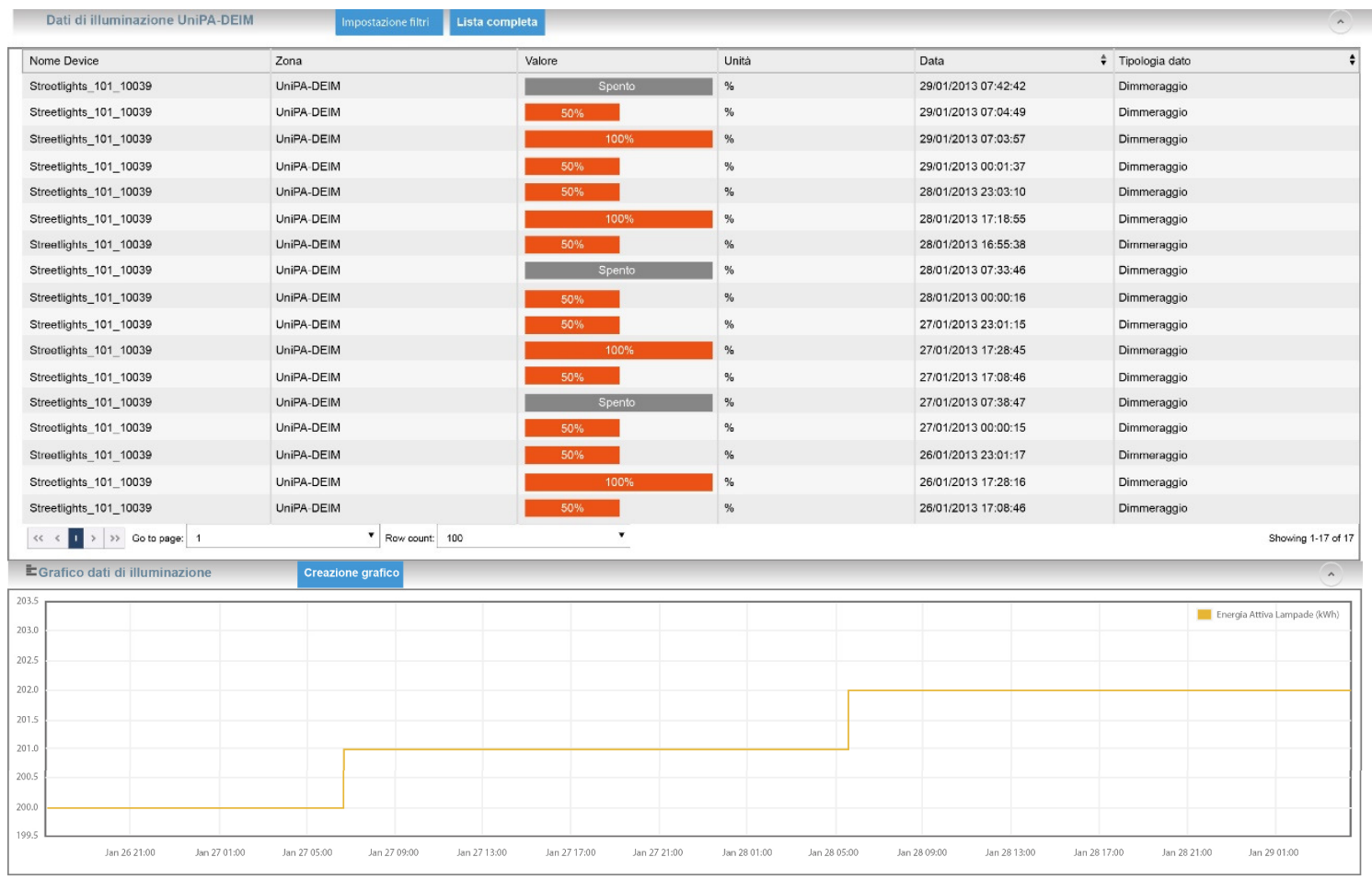

Figure 13. Screenshots from the Web application for "Public lighting" monitoring and control

\section{CONCLUSION}

Experimental tests in Palermo and Carini provided good results in terms of reliability of the global infrastructure. From the Centro Servizi node, it was possible to monitor and control the two remote systems using the two gateways, the compact adapters, the LAN, and the power line network. Web applications and a mobile app were used by researchers to test several operational modes with a twofold aim to assess actual energy efficiency and measurable performance of the new systems compared to traditional alternatives, and to test the reliability of hardware and software tools from the perspective of operators and other actors. In particular, several tests and measurements were conducted to assess the lighting function in the Palermo University Campus, parking control in Carini, as well as motion detection and video surveillance at both sites. Visible energy savings was achieved due to the reduction of installed power and new control operations integrated with weather station sensors. Solar radiation sensors provided input for the algorithm of luminance assessment and the dimmer. Rain sensors alerted the system in cases of heavy rain, ensuring extra lighting for safety. During night time a range of maximum flux reduction motion detection sensors increased the lighting levels for 15-minute intervals. During the test campaign, registered daily energy consumption was $3 / 16^{\text {ths }}$ of that measured before the upgrade of the previously installed system. Park monitoring was operated through an easy and cheap device and allowed users to find and book parking spaces, and managers of car sharing or public parking facilities to check unauthorized usage. These systems were also integrated in a larger platform where several infrastructure elements and nodes can interact, including electric car charging stations, 
proactive users, energy producers, and storage. This is the paradigm of a smart grid and smart cities.

\section{AKNOWLEDGEMENT}

The paper presents results carried out in the framework of the project "iNext" (PON04a2_H) project, funded by Italian Minister of University and Research in the framework of the PON Smart Cities and Communities and Social Innovation. The project partnership includes: Università degli Studi di Palermo, ITALTEL spa, CNR ITAE, TRE (TOZZI GREEN) spa, MUOVOSVILUPPO and EXALTO srl.

\section{REFERENCES}

1. Annunziato, M., Bucci, F., Meloni, C., Moretti, F. and Pizzuti, S., GUIDELINES: The Essential Points for an efficient management of Street Lighting Systems, ENEA Report - Italian National Agency for New Technologies, Energy and Sustainable Economic Development (in Italian), 2012.

2. Beccali, M., Bonomolo, M., Ciulla, G., Galatioto, A. and Lo Brano, V., Improvement of Energy Efficiency and Quality of Street Lighting in South Italy as an Action of Sustainable Energy Action Plans, The Case Study of Comiso (RG), Energy, Vol. 92, Part 3, pp 394-408, 2015, https://doi.org/10.1016/j.energy.2015.05.003

3. Directive 2010/31/EU of the European Parliament and of the Council of 19 May 2010 on the Energy Performance of Buildings.

4. Pease, K., A Review of Street Lighting Evaluations: Crime Reduction Effects, Surveillance of Public Space: CCTV, Street Lighting and Crime Prevention, Crime Prevention Studies, Vol. 10, pp 47-76, 1999.

5. Peña-García, A., Hurtado, A. and Aguilar-Luzón, M. C., Impact of Public Lighting on Pedestrians' Perception of Safety and Well-being, Safety Science, Vol. 78, pp 142-148, 2015, https://doi.org/10.1016/j.ssci.2015.04.009

6. Falchi, F., Cinzano, P., Elvidge, C. D., Keith, D. M. and Haim, A., Limiting the Impact of Light Pollution on Human Health, Environment and Stellar Visibility, Journal of Environmental Management, Vol. 92, No. 10, pp 2714-2722, 2011, https://doi.org/10.1016/j.jenvman.2011.06.029

7. Green, J., Perkins C., Steinbach, R. and Edwards, P., Reduced Street Lighting at Night and Health: A Rapid Appraisal of Public Views in England and Wales, Health \& Place, Vol. 34, pp 171-180, 2015, https://doi.org/10.1016/j.healthplace.2015.05.011

8. Müllner, R. and Riener, A., An Energy Efficient Pedestrian aware Smart Street Lighting System, International Journal of Pervasive Computing and Communications, Vol. 7, No. 2, pp 147-161, 2011, https://doi.org/10.1108/17427371111146437

9. Beccali, M., Bonomolo, M., Galatioto, A. and Pulvirenti, E., Smart Lighting in Historic Context: A Case Study, Management of Environmental Quality: An International Journal, Vol. 28, No. 2, 2017, https://doi.org/10.1108/MEQ-06-2015-0109

10. Cho, S. and Dhingra, V., Street Lighting Control based on LonWorks Power Line Communication, Power Line Communications and its Applications, ISPLC 2008, IEEE International Symposium, pp 396-398, 2008.

11. Lau, S. P., Merrett, G. V., Weddell, A. S. and White, N. M., A Traffic-aware Street Lighting Scheme for Smart Cities using Autonomous Networked Sensors, Computers \& Electrical Engineering, Vol. 45, pp 192-207, 2015, https://doi.org/10.1016/j.compeleceng.2015.06.011

12. Jin, D., Hannon, C., Li, Z., Cortes, P., Ramaraju, S., Burgess, P. and Shahidehpour, M., Smart Street Lighting System: A Platform for Innovative Smart City Applications and a New Frontier for Cyber-security, The Electricity Journal, Vol. 29, No. 10, pp 28-35, 2016, https://doi.org/10.1016/j.tej.2016.11.011 
13. al Irsyad, M. I. and Nepal, R., A Survey based Approach to estimating the Benefits of Energy Efficiency Improvements in Street Lighting Systems in Indonesia, Renewable and Sustainable Energy Reviews, Vol. 58, pp 1569-1577, 2016, https://doi.org/10.1016/j.rser.2015.12.294

14. Kathiresan, R., Kenneth, Y. J., Panda, S. K., Reindl, T. and Das, P., An interactive LED Lighting Interface for High Energy Savings, Innovative Smart Grid Technologies-Asia, IEEE, ISGT Asia, pp 508-513, 2014.

15. Bellido-Outeiriño, F. J., Quiles-Latorre, F. J., Moreno-Moreno, C. D., Flores-Arias, J. M., Moreno-García, I. and Ortiz-López, M., Streetlight Control System based on Wireless Communication over DALI Protocol, Sensors, Vol. 16, No. 5, 597 p, 2016, https://doi.org/10.3390/s16050597

16. Simhas, D. and Popovici, C., A Smart Grid Application-street Lighting Management System, UPB Sci. Bull. C, Vol. 75, No. 1, pp 309-324, 2013.

17. Jagadeesh, Y. M., Akilesh, S. and Karthik, S., Intelligent Street Lights, Procedia Technology, Vol. 21, pp 547-551, 2015, https://doi.org/10.1016/j. protcy.2015.10.050

18. Popa, M. and Marcu, A., A Solution for Street Lighting in Smart Cities, Carpathian Journal of Electronic and Computer Engineering, Vol. 5, 91 p, 2012.

19. Dalla Costa, M. A., Schuch, L., Michels, L., Rech, C., Pinheiro, J. R. and Costa, G. H., Autonomous Street Lighting System based on Solar Energy and LEDs, Industrial Technology (ICIT), 2010 IEEE International Conference, pp 1143-1148, 2010.

20. iNext Project, http://www.ponrec.it/open-data/risultati/smart-cities/pon04a2_h/, [Accessed: 21-February-2017]

21. Annunziato, M., Bucci, F., Meloni, C., Moretti, F. and Pizzuti, S., Smart Systems development for "Smart Street" management. ENEA Report - Italian National Agency for New Technologies, Energy and Sustainable Economic Development (in Italian), 2011.

22. Lau, S. P., Merrett, G. V., Weddell, A. S. and White, N. M., A Traffic-aware Street Lighting Scheme for Smart Cities using Autonomous Networked Sensors, Computers \& Electrical Engineering, Vol.45, pp 192-207, 2015, https://doi.org/10.1016/j.compeleceng.2015.06.011

23. Mlynek, P., Misurec, J., Kolka, Z., Slacik, J. and Fujdiak, R., Narrowband Power Line Communication for Smart Metering and Street Lighting Control, IFAC-PapersOnLine, Vol. 48, No. 4, pp 215-219, 2015, https://doi.org/10.1016/j.ifacol.2015.07.035

24. iNext (PON04a2_H): Report Att. 6.2: Study and definition of Functions for Energy efficiency Support, an Overlay-grid Smart management for a Sustainable Mobility (EXALTO) (in Italian).

25. Dialux Software, [Accessed: 21-February-2017]

http://www.dial.de/DIAL/it/dialux.html,

26. EN 13201:2004, Light and Lighting, Road Lighting - Part 2, 3, 4: Performance Requirements, Calculation of Performance, Methods of Measuring Lighting.

27. EC 1-2013 UNI 11248:2012, Light and Lighting, Road Lighting - Selection of Lighting Classes.

28. Vartiainen, E., A Comparison of Luminous Efficacy Models with Illuminance and Irradiance Measurements, Renewable Energy, Vol. 20, No. 3, pp 265-277, 2000, https://doi.org/10.1016/S0960-1481(99)00115-9

29. Meteonorm Software, http://meteonorm.com/en/, [Accessed: 21-February-2017] 